\title{
Impact of Artisanal Gold Mining on Human Health and the Environment in the Batouri Gold District, East Cameroon
}

\author{
Obase Ralph ${ }^{1,2, *}$ \\ Ngoran Gilles ${ }^{2,3}$ \\ Nde Fon ${ }^{4}$ \\ Henry Luma ${ }^{5}$ \\ Ngwane Greg ${ }^{6}$ \\ ${ }^{1}$ Department of Medicine, Faculty of Health Sciences, \\ University of Buea, Cameroon \\ ${ }^{2}$ Explorers 33 Consulting Agency, Yaoundé, Cameroon \\ ${ }^{3}$ Ministry of Mines, Industry and Technological \\ Development, Yaoundé, Cameroon \\ ${ }^{4}$ Department of Public Health and Hygiene, Faculty of Health Sciences, \\ University of Buea, Cameroon \\ ${ }^{5}$ Medical Directorate, General Hospital, Douala, Cameroon \\ ${ }^{6}$ Safety and Quality Management Institute, \\ NEBOSH Accredited Center 932, Douala, Cameroon \\ Corresponding Author
}

Doi: 10.2478/ajis-2018-0003

\section{Abstract}

There is no Occupational Health and Safety (OHS) system for the mining sector in Cameroon, and miners are exposed to numerous health and safety risks inherent from Artisanal Gold Mining (AGM) activity. Also very few studies have addressed the health problems in AGM in Cameroon. This study seeks to create an awareness of the health and environmental issues surrounding the mining sector in Cameroon so as to foster its development. It was a cross-sectional, observational, and communitybased study involving 273 respondents from three different communities. Questionnaires and interviews were used to collect data. OHS risk assessment was conducted through direct observation and inspection of five different workplaces. Blood samples were collected and analyzed for the presence of mercury and lead. Gold miners in Batouri are exposed to the risk of physical injuries, respiratory conditions, diarrheal conditions, psychotic disorders, dermatophyte infections, helminthic infestations, malaria and musculoskeletal problems. The most common health problems among miners are musculoskeletal disorders (35.6\%), malaria (26.4\%) and hernias (14.9\%), while malaria $(18.7 \%)$ and musculoskeletal disorders (15.4\%) are common among stakeholders. The mean blood mercury and lead levels among miners is $2.27 \pm 8.85 \mu \mathrm{g} / \mathrm{L}$ and $12.73 \pm 32.73 \mu \mathrm{g} / \mathrm{L}$ respectively, and $9.1 \%$ of them are chronically intoxicated with mercury, reporting $\geq 4$ symptoms possibly related to mercury intoxication. The major environmental problems are deforestation, land degradation, water pollution, air pollution and water-logged pits. AGM in Batouri, therefore, has a negative impact on human health and environmental sustainability.

Keywords: Impact; artisanal gold mining; occupational health and safety; environment; Cameroon 


\section{Introduction}

Artisanal and small-scale mining (ASM) are mining operations which are easily controlled technologically and financially by under-equipped populations with limited means and exploited as individuals, families, associations or cooperatives (Seydou, 2002). An estimated 20 million people around the world rely on ASM for livelihood, working in more than 80 countries. They produce some $10 \%$ of the world's mined gold (The World Bank, 2013).

Cameroon is a resource-rich country that has strong geological potential for a number of minerals including gold, bauxite, cobalt-nickel, iron and diamonds among others (Joseph \& Joseph, 2013). Artisanal gold mining (AGM) has been taking place in Cameroon predominantly in the eastern and northern regions since 1934, with Batouri being one of the major gold mining districts (Asaah, 2010). The total number of people involved in AGM in Cameroon is out of control, however, about 2000 miners were involved in AGM in Batouri (Samuel et al., 2007). The artisanal mining sector was organized even before national independence, contributing up to $20 \%$ of the economy (Tieguhong et al., 2009). Generally, there are two types of mining exploitation in Cameroon - the artisanal and the semi-mechanized mining. The mining processes are basically the same for both but only differ in their degrees of mechanization - in artisanal mining, rudimentary tools like spades, shovels, pickaxes and crowbars are used, while the semi-mechanized mining involves the use of heavy machines like excavators and bulldozers. However, both forms of exploitation are classified as artisanal and small-scale mining (ASM). The current annual production of gold in Cameroon is estimated at $1,500 \mathrm{~kg}$ but no modern exploitation methods have been used to locate Cameroon's primary gold potential (Tieguhong et al., 2009).

The benefits of AGM include job creation and opportunities for local companies, infrastructure and social/community development and financial income (Tiffany, 2012). On the other hand, mining can adversely affect public health and safety, and the environment (Hermanus, 2007). Because these miners are unskilled, underequipped and not knowledgeable, they have little appreciation of the health and environmental impacts of this activity (Samuel M. , 2011).

AGM is a dangerous activity as it is a potential source of heavy metal (mainly mercury, lead) contamination and toxicity (Jason et al., 2002). Mercury $(\mathrm{Hg})$ is poisonous to both humans and the environment. Chronic exposure to mercury damages the neurological system causing sensory, motor and cognitive disorders (Rasheed \& Amuda, 2014). Lead (Pb) is a major metal in goldsuphide deposits occurring as mineral mainly in galena (PbS). This is stable under natural conditions, however, once mining has taken place, it is broken down due to exposure to oxygen and water (Jason, Winnie, \& Monica, 2002). Exposure to lead takes place mostly through drinking water, breathing polluted air or dust, and eating contaminated food, for example, food grown on soil with high $\mathrm{Pb}$ content. The main target for lead toxicity is the nervous system (UNEP/OCHA, 2010).

Inhalation of large amounts of siliceous dust, careless handling of mercury during gold panning and gold/mercury amalgam processing, existence of water logged pits and trenches; and large number of miners sharing poor quality air in the mines are the major causes of health hazards among miners (Jason et al., 2002). The most common occupational diseases that workers are likely to develop as a result of long-term exposure in the gold mining environment are silicosis, silicotuberculosis, pulmonary tuberculosis (TB), obstructive airways disease, occupational asthma, oral and/or nasal cavity erosions, diseases owing to ionization radiation, noise-induced hearing loss, whole body and hand-arm vibration syndrome, as well as repetitive strain injuries (Borralho, 2013).

The process of mining also causes environmental destruction (land, soil, vegetation) leading to loss of forest resources, wildlife habitat, and/or agricultural cropland (Tiffany, 2012).

Studies on the health impacts of AGM have not been extensively carried out in Cameroon. However, in Bétaré-Oya most miners appear physically well fit, though they report backaches, muscle aches, hernias, respiratory conditions, and high prevalence of malaria (Samuel, Charles, \& Gilbert , 2007). The main environmental damage in this region is soil degradation, land damage and river pollution (Tiffany, 2012). Also, the presence of several abandoned open pits scattered in areas of ancient or recent gold mining causes severe disturbance of the land surface and disappearance of cultivable land and gallery forest (Joseph \& Joseph, 2013). 


\subsection{Justification for the study}

There is no occupational health and safety (OHS) system for the mining sector in Cameroon when compared to other economic sectors such as manufacturing, construction and rail, leading to mining's reputation as the most hazardous industrial sector (Hermanus, 2007). The risks associated with these operations are therefore not well understood. Also in Cameroon, several studies on the environmental impacts of AGM have been reported by workers such as Suh $($ Cheo, 2012) and Joseph (Joseph \& Joseph, 2013) etc., but there have been no studies on the health impacts. This study, therefore, seeks to create an awareness of the health and environmental issues surrounding the mining sector in Cameroon, so as to foster its development without any adverse implications on sustainable development. The information provided can also be used as a base-line to the development of an OHS system for the mining sector in Cameroon.

\subsection{Objectives}

The main objective of this study was to assess the health and environmental impacts of AGM in the Batouri gold district, taking evidence from three communities - Kambélé, Dem and Batouri town. The specific objectives were to:

1. Assess the occupational health and safety risks associated with artisanal gold mining in the Batouri gold district.

2. Identify the major health problems among miners and individuals living in the mining communities.

3. Assess the toxic health effects of mercury and lead exposures from mining activities.

4. Assess and semi-quantify the extent of environmental problems caused by artisanal gold mining activities in the Batouri gold district.

\section{Materials and Methods}

\subsection{Study area and setting}

This study was a cross-sectional, observational, community-based study conducted over a period of four months from November 2015 to February 2016. The target population of study corresponds to the Batouri gold district located in the East Region of Cameroon (Figure 1a). It is the second largest municipality in the Region, after Bertoua, the regional capital. It has a total population of 88,871 inhabitants, principally made up of the natives Kako, Gbaya, Bororo and refugees from Central African Republic.

There are several mining villages (communities) in Batouri as shown in the map but this study was, however, limited to the prospective areas around Kambélé, Dem and Batouri town (Figure 1b). Kambélé is a small village located in the north eastern part of Batouri town, some $10 \mathrm{~km}$ away from it. It has a population of 6,965 inhabitants. It is the major mining village in the Batouri gold district recognized for its huge potential for gold that has attracted many companies. Access within the mining sites is by tracks and forest roads. The main economic activity is AGM with more than twothird of the population involved either as part-time or full time. The remainder of population is engaged in subsistence farming. The gold exploitation is both artisanal and semi-mechanized. The artisanal gold exploitation is carried out principally by the natives (artisans) with the use of rudimentary materials such as pickaxes, diggers, shovels, spades, pans and water pumps. The activity does not respect age and gender and in some households both the parents and children are involved. Men are generally involved in heavy manual tasks like digging while women act as panners (washers) and food vendors at the mining sites. 


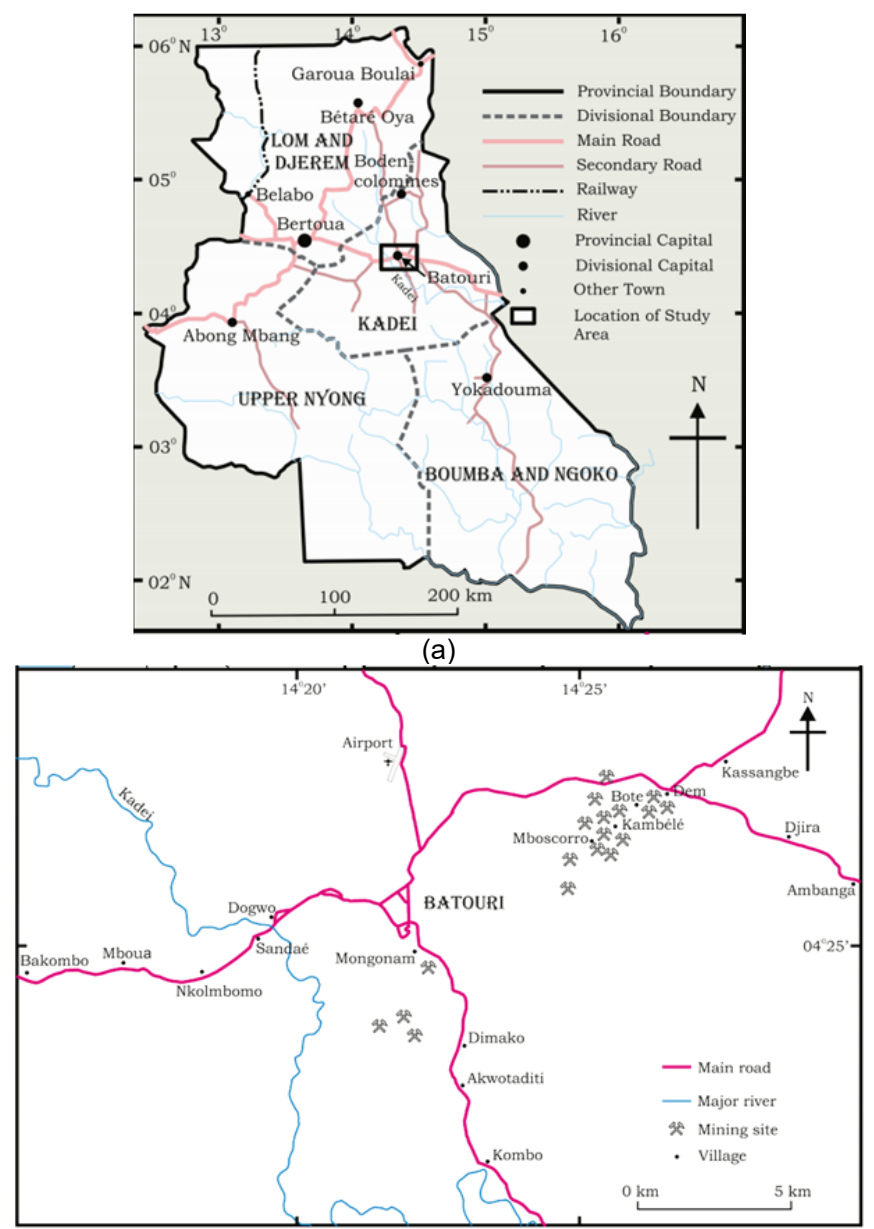

(b)

Figure 1. Location map of Batouri gold district: (a) Road map showing the Divisions of Eastern Region of Cameroon and location of Baouri (black arrow); (b) Map of Batouri gold district showing major AGM areas [4].

\subsection{The study population and sampling}

The target population of study was divided into two main groups: the miners and the stakeholders. The stakeholder population included all the natives (i.e. non-miners) living in the mining communities, and other local government authorities such as the chiefs, the Divisional Delegation of Mines and Energy, the Divisional Officer (DO), the Batouri Rural Council (BRC), the Delegation of Water and Energy Resources, the Batouri District Health Service (DHS), the Batouri District Hospital, and the Support and Promotion Framework of Small-Scale Mining in Cameroon (CAPAM). Subjects who were miners whether active or retired and who had been working for at least 1 year, and any individual greater 21 old and living in the mining community for at least 1 year were included in the study.

The study adopted stratified random and convenient methods of sampling (Kwesu \& Zhanje, 2004). The sampling frame constituted Batouri town and all the surrounding mining villages (Figure 1b). In quantitative terms, 174 miners and 99 stakeholders were recruited, giving a total of 273 
respondents as the actual sample size for the study. An Ethical Approval was obtained from the Faculty of Medicine and Pharmaceutical Sciences of the University of Douala. An authorization was obtained from the Support and Promotion Framework of Artisanal Mining (CAPAM) in Cameroon. Finally, an Administrative Approval was obtained from the Regional Delegation of Public Health for the Eastern Region.

\subsection{Study procedures}

The study was carried out on four fronts:

I. Community outreach and door-to-door surveys were conducted with the use of semistructured interviews and pre-tested questionnaires, to collect socioeconomic and other data on various ways the people interact with their environment, and their notions on how AGM is affecting their health and their environment.

II. Clinical examination of subjects for features of mercury and lead toxicity was conducted. Forty-four whole blood samples were drawn from miners and individuals living in proximity to active mining sites. The samples were labeled, frozen and transported to the University of Dschang for analysis of $\mathrm{Hg}$ and $\mathrm{Pb}$.

III. Workplaces were inspected using Hazard Identification and Risk Assessment Forms. Identification of hazards was done with the use of a Workplace Inspection Checklist (Appendix 1). Generally, five different workplaces were identified - digger craftsmen, crushers, millers, washers and panners. The hazards inherent to each of these workplaces were identified and documented through direct observation and analysis of the tasks, tools and the processes related to their use. The checklist was adopted from an OHS system for small-scale mines in Rwanda (Bernd et al., 2010). Features inspected according to the checklist included: supervision; use of personal protective equipment (PPE); use of first aid measures; observation of persons under influence of alcohol; reported incidences of verbal, physical or sexual harassment; hygiene and sanitation; pit wall stability; access paths, ramps and roads; and mine water. The risk analysis was done using an adopted Risk Analysis Form (Appendix 2). Risk is the likelihood that exposure to a hazard will lead to injury or health problem (Bernd, Jennifer, \& Manfred, 2010). In relation to each hazard, the researcher identified what could happen, how it could happen, why it could happen, persons at risks, mode of exposure to the hazard and existing control measures. Finally, the "likelihood of exposure" and the "consequences of exposure" to each of the hazards were assessed. A qualitative approach to risk assessment was then employed using the formula: Risk $=$ [Likelihood] $\times$ [Consequence $]$. The risk was then rated as either "High", "Medium" or "Low" using a matrix table. According to this rating High Risk is intolerable, Medium Risk has to be reduced to as low as reasonably practicable level, and Low Risk is tolerable.

IV. Desk research was conducted at the Église Presbytérien du Cameroun (EPC) Hospital of Kambélé and the Batouri District Health Service. Outpatient registers were assessed for common diseases in Kambélé for the past 6 months, and monthly surveillance of major public health problems in the district for the year 2015 were documented respectively.

\subsubsection{Sample preparation and analysis}

The blood samples were frozen and transported to a specialized laboratory in the Faculty of Agronomy and Agricultural Engineering of the University of Dschang. There, $7.5 \mathrm{ml}$ of concentrated $\mathrm{HNO}_{3}$ and $2.5 \mathrm{ml}$ of concentrated $\mathrm{HCl}$ were added to $1 \mathrm{ml}$ of blood and heated at temperatures of $80-90^{\circ}$ until emission of nitrous vapor. The residual volume was then made to reach $50 \mathrm{ml}$ using distilled ionized water. At this stage, the samples were ready for $\mathrm{Hg}$ and $\mathrm{Pb}$ analysis using Atomic Absorption Spectrometer. 


\section{Results}

\subsection{Demographic and socioeconomic profiles}

A total of 273 respondents (174 miners and 99 stakeholders) were recruited from three different communities classified into 'mining' (Kambélé and Dem) and 'non-mining' (Batouri town) communities (Table 1). Majority of the respondents (38.5\%) were between the ages $26-35$ years with a male predominance. The highest level of education attained by most miners (33.0\%) was primary education while for the stakeholders $(20.9 \%)$ it was secondary. There was a significant difference $(P<0.001)$ in schooling between miners and stakeholders, and school enrolment was significantly $(P=0.009$ ) lower in the mining communities when compared to the non-mining community. A majority of the miners had been doing AGM for $1-5$ years, working on average $23 \pm$ 5 days in a month, and obtaining $3.44 \pm 2.2$ grams of gold every week. Their mean monthly income calculated as a direct measure of the quantity of gold obtained, using 15,000 FCFA as the standard unit cost of $1 \mathrm{~g}$ of gold was 206,400 $\pm 131,980$ FCFA. Among the various challenges faced by the artisanal miners, the lack of adequate working materials appeared to be the priority problem (Figure 2).

Table 1. Background characteristics of respondents.

\begin{tabular}{|c|c|c|c|c|c|}
\hline \multicolumn{2}{|l|}{ Variable } & $\begin{array}{c}\text { Miners } \\
\text { N (\%) }\end{array}$ & $\begin{array}{c}\text { Stakeholders } \\
\text { N (\%) }\end{array}$ & $\begin{array}{l}\text { Total } \\
\text { N (\%) }\end{array}$ & P-value \\
\hline \multicolumn{6}{|l|}{ Community } \\
\hline \multicolumn{2}{|c|}{ Kambélé } & $102(37.4)$ & $45(16.5)$ & $147(54)$ & \\
\hline \multicolumn{2}{|l|}{ Dem } & $66(24.2)$ & $24(8.8)$ & $90(33)$ & $<0.001$ \\
\hline \multicolumn{2}{|c|}{ Batouri town } & $6(2.2)$ & $30(11.0)$ & $36(13.2)$ & \\
\hline \multicolumn{6}{|l|}{ Gender } \\
\hline \multicolumn{2}{|l|}{ Males } & $132(48.4)$ & $57(20.9)$ & $189(69.2)$ & \\
\hline \multicolumn{2}{|l|}{ Females } & $42(15.5)$ & $42(15.4)$ & $84(30.8)$ & 0.002 \\
\hline \multicolumn{6}{|c|}{ Age (years) } \\
\hline 1) & $18-25$ & $42(15.4)$ & $15(5.5)$ & $57(20.9)$ & \multirow{4}{*}{0.001} \\
\hline & $26-35$ & $66(24.2)$ & 39 (14.3) & $105(38.5)$ & \\
\hline & $36-50$ & $42(15.4)$ & $42(15.4)$ & $30.8)$ & \\
\hline 4) & $>50$ & $24(8.8)$ & $3(1.1)$ & $27(9.9)$ & \\
\hline \multicolumn{6}{|c|}{ Education } \\
\hline 1) & No schooling & $30(11.0)$ & $9(3.3)$ & $39(14.3)$ & \multirow{4}{*}{$<0.001$} \\
\hline 2) & Primary & $90(33.0)$ & $12(4.4)$ & $102(37.4)$ & \\
\hline 3) & Secondary & $54(19.8)$ & 57 (20.9) & $111(40.7)$ & \\
\hline 4) & Tertiary & $0(0.0)$ & $21(7.7)$ & $21(7.7)$ & \\
\hline \multicolumn{6}{|c|}{ Occupation as a miner } \\
\hline \multicolumn{2}{|c|}{ Full time } & $114(65.5)$ & - & $114(65.5)$ & \\
\hline \multirow{2}{*}{\multicolumn{2}{|c|}{$\begin{array}{l}\text { Part time } \\
\text { Duration in mining }\end{array}$}} & $60(34.5)$ & - & $60(34.5)$ & \\
\hline & \\
\hline 1) & $1-5$ years & $54(31.0)$ & - & $54(31.0)$ & \\
\hline 2) & $6-10$ years & $48(27.6)$ & - & $48(27.6)$ & \\
\hline 3) & $11-15$ years & $36(20.7)$ & - & $36(20.7)$ & \\
\hline 5) & $>20$ years & $36(20.7)$ & - & $36(20.7)$ & \\
\hline \multicolumn{2}{|c|}{ Number of trips per month (mean \pm SD days) } & $23.48 \pm 4.871$ & - & - & \\
\hline \multicolumn{2}{|c|}{ Quantity of gold obtained per week (mean \pm SD grams) } & $3.44 \pm 2.20$ & - & - & \\
\hline & $206,400 \pm 131,981.69$ & - & - & \\
\hline \multicolumn{6}{|c|}{ Are you aware any regulations or policies } \\
\hline \multicolumn{2}{|c|}{ Yes } & $36(23.1)$ & $30(34.5)$ & $66(27.2)$ & \\
\hline \multicolumn{2}{|l|}{ No } & $120(76.9)$ & $57(65.5)$ & $144(59.3)$ & $<0.001$ \\
\hline \multicolumn{2}{|l|}{ Don't know } & $0(0.0)$ & $33(37.9)$ & $33(13.6)$ & \\
\hline
\end{tabular}




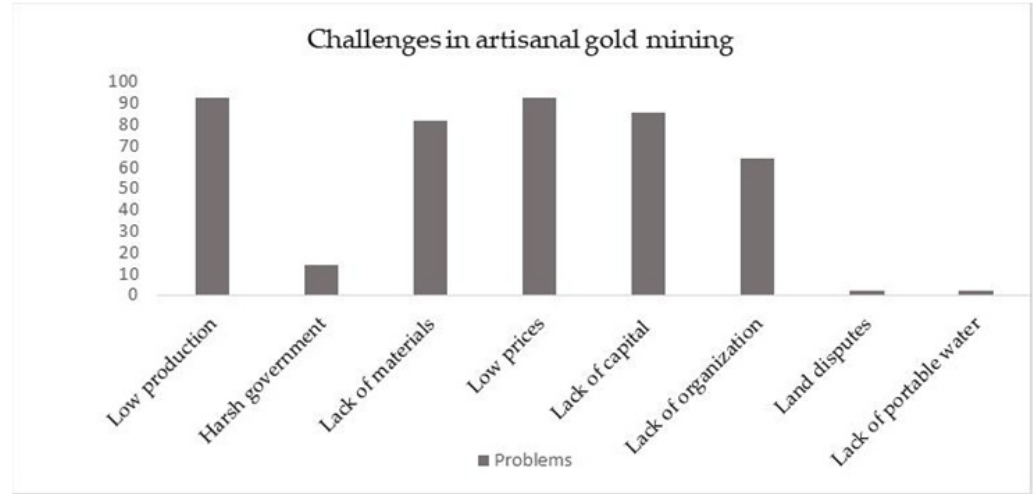

(a)

Proposed solutions to challanges in AGM

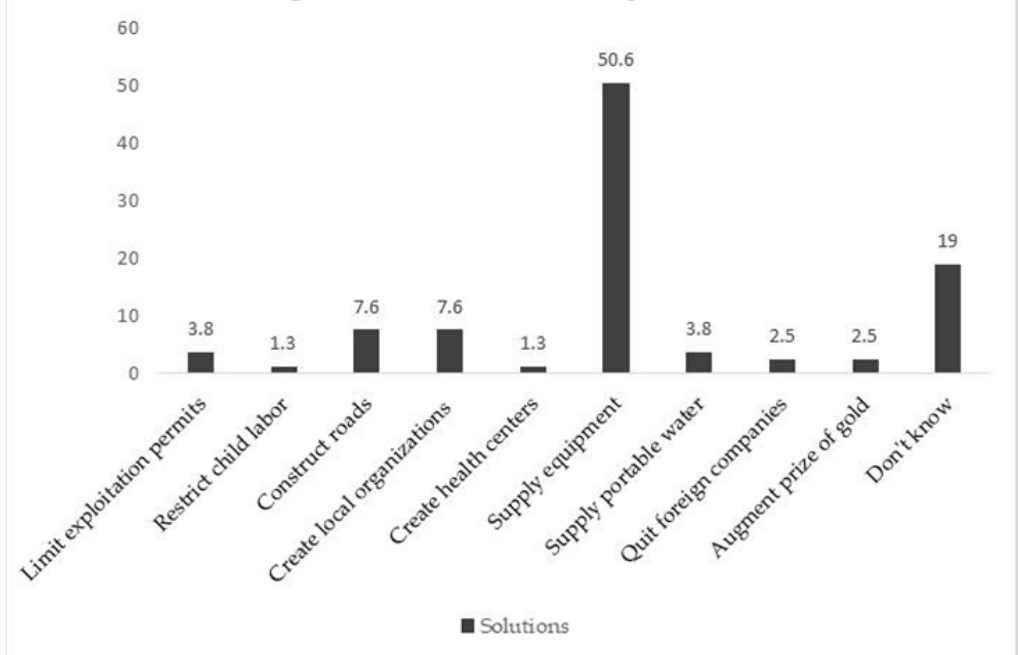

(b)

Figure 2. Challenges in artisanal gold mining: (a) Major challenges faced by miners; (b) Proposed solutions.

\subsection{Hazard identification and risk assessment}

\subsubsection{Workplaces and job description.}

Generally, five different workplaces were identified as shown in the summary of the entire mining process in figure 3 below. The job description related to each workplace is also summarized.

- The digger-craftsmen are responsible for ore extraction through digging of open-pits or underground galleries using rudimentary tools or excavators.

- The crushers are responsible for fragmenting the crude ore, separating them from impurities contained within the mineralized gravel using hammers and heavy metal rods. They work on the ground in sitting positions, with outstretched legs or bent knees and unsupported backs. They hold the mineralized rock on a hard surface with one hand, and hit repeatedly with the other hand using hammers or heavy metal rods.

- The millers are responsible for further separating the crushed ores into finer particles using 
adapted grinding mills. They work in standing positions and control the crushed gravels with the other hands into the grinding mill.

- The washers are responsible for separating mineralized gravel from impurities and concentrating the gold using water pumps and sluice boxes. The sluice boxes have perforating grating surfaces. Their hands and feet are constantly in waters.

- The panners are in charge of concentrating the washed or grinded products using aluminum pans and water. Their hands and feet are frequently immersed in water. At this stage, mercury is clandestinely used for amalgamation to further concentrate the gold, after which the final product is heated on locally-made fire or sun-dried.

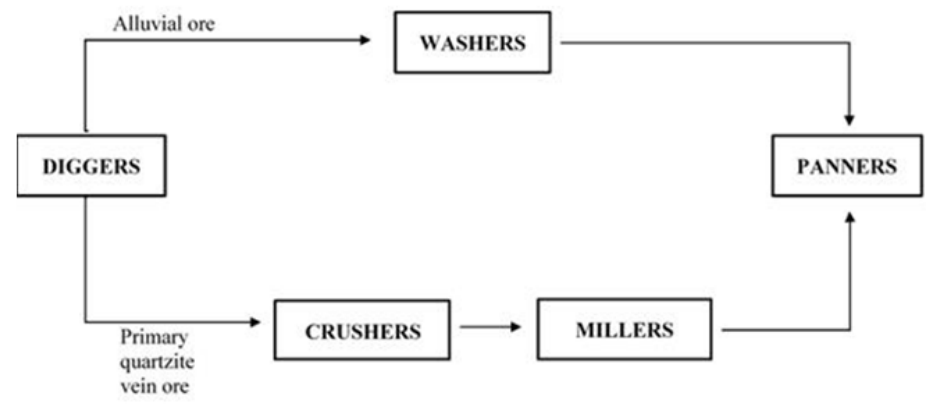

Figure 3. Schematic diagram summarizing the entire mining process and identifying five different workplaces.

\subsubsection{Hazards and risk generated by different workplaces.}

The overall trend of OHS risk in the different workplaces points to the digger-craftsman as the most hazardous workplace when compared to other workplaces (Tables 2 below). They are exposed to the risk of physical injuries and deaths from rock falls and collapse of galleries; suffocation from poor ventilation in underground mines; respiratory conditions from siliceous dust inhalation; diarrheal conditions from contamination; malaria due to exposure to mosquito vectors; psychotic disorders due to illicit drug use; noise-induced hearing loss due to noise produced by bulldozers; and heat stroke and dehydration due exposure to high temperatures. The mean number of deaths per year was approximately $6 \pm 3$. The major causes were collapse of galleries $(65.8 \%)$, subsidence $(31.6 \%)$ and others $(2.6 \%)$ like bad communication with working equipment and drowning in water-logged pits, etc. Work accidents were very frequent, occurring at least every week. Hazards that were non-specific to the workplaces include alcohol consumption, cigarette smoking, child labor, labor of pregnant women, and labor of nursing mothers (Table 2). The prevalence of alcohol consumption and cigarette smoking amongst miners was $86.2 \%$ and $41.4 \%$ respectively. The mean quantity of alcohol consumed per week was $13.64 \pm 19.65$ bottles. The mean quantity of cigarette smoked was $6.48 \pm 5.85$ pack years for an average of $12.92 \pm 10.94$ years.

\subsection{Major health problems among miners and stakeholders}

A total of $67.7 \%$ of the respondents were aware of at least one health problem caused as a result of gold mining (Tables 3 and 4). The following health problems were reported: malaria, musculoskeletal problems (low back pains, myalgia, body pains), work accidents, fatalities, hernias, STDs, diarrheal conditions (cholera and typhoid), fatigue from exhaustion, respiratory problems (persistent cough, rhinitis, breathlessness), intestinal helminths and heatstroke. Among the most common health problems faced by miners, musculoskeletal problems $(35.6 \%)$, malaria $(26.4 \%)$ and hernias $(14.9 \%)$ were the top three, while for the non-miners (stakeholders) malaria $(18.7 \%)$, 
musculoskeletal problems $(15.4 \%)$ and intestinal helminthiasis $(4.4 \%)$ topped the list. Both groups of respondents were further divided into two; those with at least one health problem (or disease) and those with none. The Pearson Chi-Square test established a statistically significant $(\mathrm{P}<0.05)$ relationship between these health problems and various socioeconomic determinants like occupation, location, gender and age, except for education $(P=0.553)$ (Table 5). The odds ratio for having these health problems as a miner when compared to a non-miner was 4.364 (2.55 - 7.47 $95 \% \mathrm{Cl}$ ) and miners were approximately twice at risk to develop these problems than non-miners. Also, those living in the mining communities where approximately two times likely exposed to these health problems when compared to those living in the non-mining community $(O R=2.158,1.031-$ $4.51595 \% \mathrm{Cl}$ ). The Spearman's rho correlations show that the relationship was strongest with monthly income and weakest with education, and shows a direct relationship with all determinants except education (Table 6). Thus, those who never went to school were more likely to develop these health problems when compared to those who went to school $(P=0.553)$.

Table 2. Occupational health and safety risk assessment in the different workplaces of artisanal gold mining in Batouri.

\begin{tabular}{|c|c|c|c|c|}
\hline Hazard & Possible risk & $\begin{array}{c}\text { Likelihood } \\
\text { level }\end{array}$ & Consequence & $\begin{array}{c}\text { Risk } \\
\text { rating } \\
\end{array}$ \\
\hline \multicolumn{5}{|l|}{ Digger-craftsmen } \\
\hline $\begin{array}{l}\text { 1. Working in pit while excavator is } \\
\text { operating overhead }\end{array}$ & Physical injury from falling rocks and gravel & Likely & Catastrophic & High \\
\hline $\begin{array}{l}\text { 2. Pilling of overburden at pit wall } \\
\text { edge }\end{array}$ & Physical injury from falling rocks and gravel & Likely & Moderate & Medium \\
\hline 3. Undercutting of pit wall & Physical injury from collapse of pit wall & Likely & Major & High \\
\hline 4. Existence of water-logged pits & Breeding of mosquitoes, vectors for malaria & $\begin{array}{l}\text { Almost } \\
\text { certain }\end{array}$ & Moderate & High \\
\hline 5. Defecating in bushes and waters & $\begin{array}{l}\text { Diarrheal conditions like cholera and typhoid } \\
\text { from contamination }\end{array}$ & $\begin{array}{l}\text { Almost } \\
\text { certain }\end{array}$ & Moderate & High \\
\hline 6. Drinking of mine water & $\begin{array}{l}\text { Diarrheal conditions like cholera and typhoid } \\
\text { from contamination }\end{array}$ & Likely & Moderate & Medium \\
\hline 7. Inhalation of siliceous dust in air & $\begin{array}{l}\text { Respiratory conditions - silicosis, silico-TB, } \\
\text { COPD. }\end{array}$ & $\begin{array}{l}\text { Almost } \\
\text { certain }\end{array}$ & Moderate & High \\
\hline $\begin{array}{l}\text { 8. Working in underground galleries } \\
\text { and tunnels }\end{array}$ & Collapse of gallery & Possible & Catastrophic & High \\
\hline $\begin{array}{l}\text { 9. Poor ventilation of underground } \\
\text { mines }\end{array}$ & Suffocation & Possible & Moderate & Medium \\
\hline $\begin{array}{l}\text { 10. Exposure to high temperatures in } \\
\text { galleries and open pits }\end{array}$ & Heat stroke or dehydration & Possible & Moderate & Medium \\
\hline 11. Noise produced by excavator & Noise-induced hearing loss & $\begin{array}{l}\text { Almost } \\
\text { certain }\end{array}$ & Major & High \\
\hline $\begin{array}{l}\text { 12. Use of illicit drugs and opiate } \\
\text { analgesic (tramadol hydrochloride) } \\
\text { Washers }\end{array}$ & Psychotic disorders & Alost certain & Major & High \\
\hline 1. Hands and feet constantly in water & $\begin{array}{l}\text { Dermatophyte (onychomycosis, athlete's foot) } \\
\text { and helminthic infestations. }\end{array}$ & $\begin{array}{l}\text { Almost } \\
\text { certain }\end{array}$ & Moderate & High \\
\hline $\begin{array}{l}\text { 2. Defecating in surrounding bushes } \\
\text { and water }\end{array}$ & $\begin{array}{l}\text { Diarrheal conditions from contamination } \\
\text { (cholera, typhoid) }\end{array}$ & $\begin{array}{l}\text { Almost } \\
\text { certain }\end{array}$ & Moderate & High \\
\hline 3. Prolonged standing and stooping & Musculoskeletal problems (low back pains) & $\begin{array}{l}\text { Almost } \\
\text { certain }\end{array}$ & Minor & Medium \\
\hline $\begin{array}{l}\text { 4. No protection means between } \\
\text { hands and grating parts of sluice } \\
\text { boxes }\end{array}$ & Digital injury & $\begin{array}{l}\text { Almost } \\
\text { certain }\end{array}$ & Minor & Medium \\
\hline \multicolumn{5}{|l|}{ Crushers } \\
\hline 1. Flying rock particles in air & Ocular trauma & $\begin{array}{l}\text { Almost } \\
\text { certain }\end{array}$ & Moderate & High \\
\hline $\begin{array}{l}\text { 2. Exposed fingers to oscillating } \\
\text { hammer }\end{array}$ & Digital injury & $\begin{array}{l}\text { Almost } \\
\text { certain }\end{array}$ & Minor & Medium \\
\hline 3. Bad sitting positions & Musculoskeletal problems (low back pains) & $\begin{array}{l}\text { Almost } \\
\text { certain }\end{array}$ & Minor & Medium \\
\hline 4. Inhalation of siliceous dust particles & $\begin{array}{l}\text { Respiratory problems such as silicosis, silico- } \\
\text { tuberculosis and COPD }\end{array}$ & $\begin{array}{l}\text { Almost } \\
\text { certain }\end{array}$ & Moderate & High \\
\hline 5. Repeated motions of the limb & $\begin{array}{l}\text { Repetitive stress injuries (tendynitis, carpal- } \\
\text { tunnel syndrome, osteoarthritis of the wrist } \\
\text { etc.) }\end{array}$ & $\begin{array}{l}\text { Almost } \\
\text { certain }\end{array}$ & Moderate & High \\
\hline
\end{tabular}




\begin{tabular}{|c|c|c|c|c|}
\hline Hazard & Possible risk & $\begin{array}{l}\text { Likelihood } \\
\text { level }\end{array}$ & Consequence & $\begin{array}{l}\text { Risk } \\
\text { rating }\end{array}$ \\
\hline \multicolumn{5}{|l|}{ Millers } \\
\hline 1. Siliceous dust inhalation & Respiratory conditions & $\begin{array}{l}\text { Almost } \\
\text { certain }\end{array}$ & Moderate & High \\
\hline 2. Prolonged standing & Musculoskeletal disorders like low back pains & $\begin{array}{l}\text { Almost } \\
\text { certain }\end{array}$ & Minor & Medium \\
\hline 3. Noise produced by the grinding mill & Noise-induced hearing loss & $\begin{array}{l}\text { Almost } \\
\text { certain }\end{array}$ & Major & High \\
\hline \multicolumn{5}{|l|}{ Panners } \\
\hline 1. Hands and feet constantly in water & $\begin{array}{l}\text { Dermatophyte (onychomycosis, athlete's foot) } \\
\text { and helminthic infections }\end{array}$ & $\begin{array}{l}\text { Almost } \\
\text { certain }\end{array}$ & Moderate & High \\
\hline 2. Defecating in bushes and water & $\begin{array}{l}\text { Diarrheal conditions from contamination } \\
\text { (cholera, typhoid) }\end{array}$ & $\begin{array}{l}\text { Almost } \\
\text { certain }\end{array}$ & Moderate & High \\
\hline 3. Prolonged standing and stooping & Musculoskeletal problems (low back pains) & $\begin{array}{l}\text { Almost } \\
\text { certain }\end{array}$ & Minor & Medium \\
\hline 4. Prolonged exposure to sun & Heat stroke and dehydration & $\begin{array}{l}\text { Almost } \\
\text { certain }\end{array}$ & Minor & Medium \\
\hline \multicolumn{5}{|l|}{ Non-specific hazards } \\
\hline 1. Drinking of alcohol while working & $\begin{array}{l}\text { Occupational injury from violence and loss of } \\
\text { self-control }\end{array}$ & $\begin{array}{l}\text { Almost } \\
\text { certain }\end{array}$ & Major & High \\
\hline 2. Cigarette smoking & $\begin{array}{l}\text { Respiratory conditions like COPD or lung } \\
\text { cancer }\end{array}$ & $\begin{array}{l}\text { Almost } \\
\text { certain }\end{array}$ & Major & High \\
\hline 3. Labor of nursing mothers & Occupational injury to baby & Likely & Catastrophic & High \\
\hline 4. Labor of pregnant women & Abortion and congenital malformations & Possible & Moderate & medium \\
\hline
\end{tabular}

Table 3. Common diseases among community members by place of residence.

\begin{tabular}{|c|c|c|c|c|c|c|}
\hline & & \multicolumn{3}{|c|}{ Place of residence } & \multirow{2}{*}{$\begin{array}{l}\text { Total } \\
\mathrm{N}(\%)\end{array}$} & \multirow[b]{2}{*}{$P$-value } \\
\hline & & $\begin{array}{l}\text { Kambélé } \\
\mathrm{N}(\%)\end{array}$ & $\begin{array}{l}\text { Batouri town } \\
\qquad \mathrm{N}(\%)\end{array}$ & $\begin{array}{c}\text { Dem } \\
\mathrm{N}(\%)\end{array}$ & & \\
\hline \multirow{2}{*}{$\begin{array}{l}\text { Are you aware of any health problems } \\
\text { caused as a result of mining? }\end{array}$} & Yes & $30(71.4)$ & $18(66.7)$ & $15(62.5)$ & $63(67.7)$ & \multirow[t]{2}{*}{0.577} \\
\hline & No & $12(28.6)$ & $9(33.3)$ & $9(37.5)$ & $30(32.3)$ & \\
\hline \multirow{8}{*}{$\begin{array}{l}\text { What is the most common health } \\
\text { problem among miners? }\end{array}$} & Malaria & $54(37.5)$ & $3(10.0)$ & $12(13.8)$ & $69(26.4)$ & \multirow{8}{*}{$<0.001$} \\
\hline & Musculoskeletal problems & $48(33.3)$ & $6(20.0)$ & $39(44.8)$ & $93(35.6)$ & \\
\hline & Work accidents & $9(6.2)$ & $0(0.0)$ & $3(3.4)$ & $12(4.6)$ & \\
\hline & Hernias & $15(10.4)$ & $3(10.0)$ & $21(24.1)$ & $39(14.9)$ & \\
\hline & Diarrheal conditions & $3(2.1)$ & $6(20.0)$ & $6(6.9)$ & $15(5.7)$ & \\
\hline & STDs & $0(0.0)$ & $3(10.0)$ & $0(0.0)$ & $3(1.1)$ & \\
\hline & Fatigue / exhaustion & $15(10.4)$ & $0(0.0)$ & $6(6.9)$ & $21(8.0)$ & \\
\hline & Respiratory problems & $0(0.0)$ & $9(30.0)$ & $0(0.0)$ & $9(3.4)$ & \\
\hline \multirow{9}{*}{$\begin{array}{l}\text { What medical condition do you have or } \\
\text { usually suffer from? }\end{array}$} & Hypertension & $3(2.0)$ & $0(0.0)$ & $0(0.0)$ & $3(1.1)$ & \multirow[t]{9}{*}{$<0.0005$} \\
\hline & Breathlessness & $0(0.0)$ & $0(0.0)$ & $6(6.7)$ & $6(2.2)$ & \\
\hline & HIVIAIDS & $0(0.0)$ & $6(16.7)$ & $0(0.0)$ & $6(2.2)$ & \\
\hline & Recurrent hernias & $6(4.1)$ & $0(0.0)$ & $6(6.7)$ & $12(4.4)$ & \\
\hline & Malaria & $42(28.6)$ & $0(0.0)$ & $9(10.0)$ & $51(18.7)$ & \\
\hline & Musculoskeletal problems & $24(16.3)$ & $3(8.3)$ & $15(16.7)$ & $42(15.4)$ & \\
\hline & Intestinal helminths & $12(8.2)$ & $0(0.0)$ & $0(0.0)$ & $12(4.4)$ & \\
\hline & Diarrheal conditions & $0(0.0)$ & $3(8.3)$ & $0(0.0)$ & $3(1.1)$ & \\
\hline & None & $60(40.8)$ & $24(66.7)$ & $54(60.0)$ & 138 (50.5) & \\
\hline \multirow{3}{*}{$\begin{array}{l}\text { Would you say these diseases are } \\
\text { related to mining? }\end{array}$} & Yes & $39(56.5)$ & $12(66.7)$ & $21(50.0)$ & $72(55.8)$ & \multirow[t]{3}{*}{$<0.0005$} \\
\hline & No & $15(21.7)$ & $0(0.0)$ & $21(50.0)$ & $36(27.9)$ & \\
\hline & Don't know & $15(21.7)$ & $6(33.3)$ & $0(0.0)$ & $21(16.3)$ & \\
\hline
\end{tabular}


Table 4. Major health problems among miners and stakeholders.

\begin{tabular}{|c|c|c|c|c|c|c|}
\hline & & $\begin{array}{l}\text { Miners } \\
N(\%)\end{array}$ & $\begin{array}{c}\text { Stakeholders } \\
\mathrm{N}(\%)\end{array}$ & $\begin{array}{l}\text { Total } \\
\text { N (\%) }\end{array}$ & $\begin{array}{l}\text { Odds ratio } \\
(95 \% \mathrm{Cl})\end{array}$ & $\begin{array}{l}\text { P-value } \\
\text { (Chi } \\
\text { square) }\end{array}$ \\
\hline $\begin{array}{l}\text { What is the most common } \\
\text { health problem among } \\
\text { miners? }\end{array}$ & $\begin{array}{l}\text { Malaria } \\
\text { Musculoskeletal problems } \\
\text { Work accidents } \\
\text { Hernias } \\
\text { Diarrheal conditions } \\
\text { STDs } \\
\text { Fatigue / exhaustion } \\
\text { Respiratory problems }\end{array}$ & $\begin{aligned} 48 & (27.6) \\
78 & (44.8) \\
0 & (0.0) \\
24 & (13.8) \\
6 & (3.4) \\
0 & (0.0) \\
18 & (10.3) \\
0 & (0.0)\end{aligned}$ & $\begin{array}{l}21(24.1) \\
15(17.2) \\
12(13.8) \\
15(17.2) \\
9(10.3) \\
3(3.4) \\
3(3.4) \\
9(10.3)\end{array}$ & $\begin{array}{c}69(26.4) \\
93(35.6) \\
12(4.6) \\
39(14.9) \\
15(5.7) \\
3(1.1) \\
21(8.0) \\
9(3.4)\end{array}$ & & $<0.001$ \\
\hline $\begin{array}{l}\text { What medical condition do } \\
\text { you have or usually suffer } \\
\text { from? }\end{array}$ & $\begin{array}{l}\text { Hypertension } \\
\text { Breathlessness } \\
\text { HIVIAIDS } \\
\text { Recurrent hernias } \\
\text { Malaria } \\
\text { Musculoskeletal problems } \\
\text { Intestinal helminths } \\
\text { Diarrheal conditions } \\
\text { None }\end{array}$ & $\begin{array}{c}0(0.0) \\
6(3.4) \\
6(3.4) \\
12(6.9) \\
36(20.7) \\
36(20.7) \\
12(6.9) \\
0(0.0) \\
66(37.9)\end{array}$ & $\begin{aligned} & 3(3.0) \\
0 & (0.0) \\
0 & (0.0) \\
0 & (0.0) \\
15 & (15.2) \\
6 & (6.1) \\
0 & (0.0) \\
3 & (3.0) \\
72 & (72.7)\end{aligned}$ & $\begin{array}{c}3(1.1) \\
6(2.2) \\
6(2.2) \\
12(4.4) \\
51(18.7) \\
42(15.4) \\
12(4.4) \\
3(1.1) \\
138(50.5)\end{array}$ & $\begin{array}{c}2.81(2.40-3.30) \\
1.59(1.45-1.74) \\
1.59(1.45-1.74) \\
1.61(1.47-1.77) \\
1.46(0.76-2.83) \\
4.043(1.64-9.98) \\
1.61(1.47-1.77) \\
2.81(2.40-3.30) \\
4.364(2.55-7.47)\end{array}$ & $\begin{array}{l}0.021 \\
0.062 \\
0.062 \\
0.008 \\
0.259 \\
0.001 \\
0.008 \\
0.021 \\
<0.001\end{array}$ \\
\hline
\end{tabular}

Table 5. Relationship between health problems in AGM and different determinants, showing the level of significance ( $P<0.005$, two-tailed Chi-square test) and risk estimates.

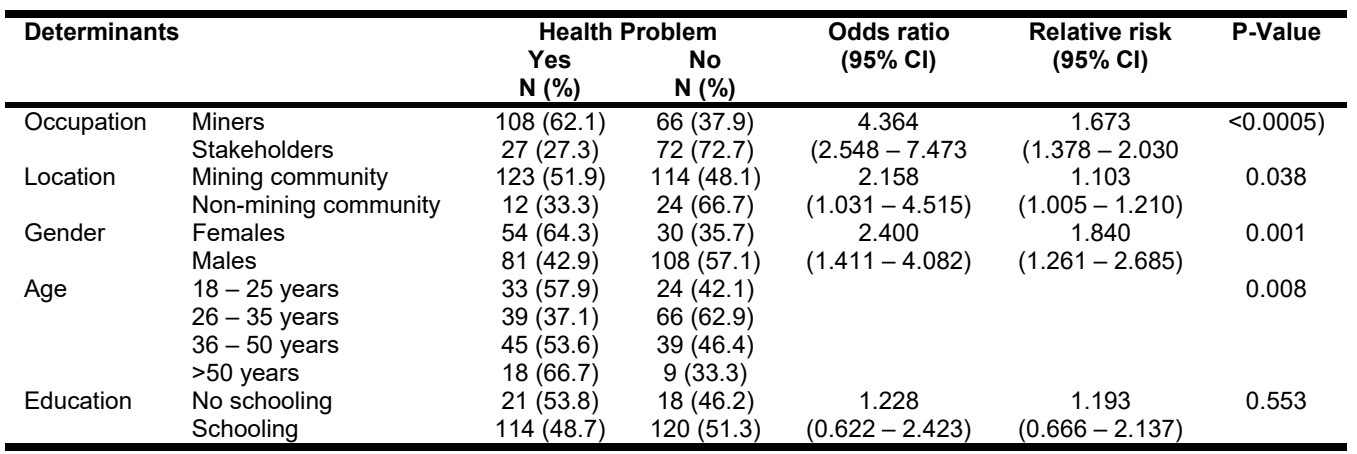

Table 6. Spearman's rho correlations between health problems in AGM and different determinants in the Batouri gold district.

\begin{tabular}{lcc}
\hline Determinants & Correlation coefficient & P-value \\
\hline Occupation (miner) & $0.335^{* *}$ & $<0.0005$ \\
Location (mining community) & $0.126^{*}$ & 0.038 \\
Gender (female) & ${ }^{* *} 0.198$ & 0.001 \\
Age (advanced age) & 0.062 & 0.307 \\
Education (schooling) & -0.036 & 0.555 \\
Education levels (higher levels) & $-0.148^{*}$ & 0.014 \\
Number of trips per month & $0.429^{* *}$ & $<0.0005$ \\
Monthly income & $0.529^{* *}$ & $<0.0005$ \\
\hline${ }^{*}$ Correlation is significant at the 0.05 level (2-tailed) & & \\
${ }^{* *}$ Correlation is significant at the 0.01 level (2-tailed) & &
\end{tabular}

\subsection{Toxic health effects of mercury and lead}

A total of $24.2 \%$ of the respondents had none of the clinical features of heavy metal exposure while 
$75.8 \%$ reported at least one features as shown in Table 12. Features which were not reported at all include: metallic taste, paresthesia and muscle weakness. The most frequent reported feature was unusual tiredness $(40.7 \%)$ and the difference between both group of respondent was significant $(P$ $=0.001)$. A total of $23.1 \%$ reported more than 3 symptoms possibly relating to mercury intoxication. Table 13 below summarizes all the total blood mercury and lead concentrations. The blood mercury and lead concentrations were higher than the CDC current reference threshold for toxicity (i.e., 10 $\mu \mathrm{g} / \mathrm{L}$ for $\mathrm{Hg}$ and $100 \mu \mathrm{g} / \mathrm{L}$ for $\mathrm{Pb}$ ) in only $9.1 \%$ and $4.5 \%$ of the samples respectively (Table 13.). The mean blood mercury and lead concentrations were $2.27 \pm 8.58 \mu \mathrm{g} / \mathrm{L}$ and $12.73 \pm 32.73 \mu \mathrm{g} / \mathrm{L}$ respectively. In majority of the samples no heavy metals are detected at all. However, there was a significant $(P<0.05)$ strong positive correlation between the clinical features observed and the blood Hg concentrations (Table 14.)

\subsection{Environmental problems caused by mining}

A total of $83.8 \%$ of the respondents were aware of environmental problems caused by mining. They reported the following problems: deforestation, soil destruction, water pollution, and existence of stagnant waters (Figure 4). Vulnerable elements to these environmental problems were water, soil, vegetation, grass, land, people, wildlife, agricultural activities and aquatic life (figure 5). The most vulnerable among these elements was water. A semi-quantitative assessment of the extent of these problems revealed that land degradation, water pollution, and deforestation were of greater extent (Figure 6).

Table 7. Clinical features of mercury and lead exposures among miners and stakeholders in the Batouri gold district.

\begin{tabular}{|c|c|c|c|c|c|}
\hline Clinical feature & $\begin{array}{c}\text { Miners } \\
\text { N (\%) }\end{array}$ & $\begin{array}{c}\text { Stakeholders } \\
\mathbf{N}(\%)\end{array}$ & $\begin{array}{l}\text { Total } \\
\text { N (\%) }\end{array}$ & $\begin{array}{c}\text { Odds Ratio } \\
(95 \% \mathrm{Cl})\end{array}$ & P-value \\
\hline Frequent headaches & $66(37.9)$ & $36(36.4)$ & $102(37.4)$ & $1.07(0.64-1.78)$ & 0.797 \\
\hline Insomnia & $6(3.4)$ & $12(12.1)$ & $18(6.6)$ & $0.26(0.095-0.71)$ & 0.006 \\
\hline Mood swings & $0(0.0)$ & $9(9.1)$ & $9(3.3)$ & $2.93(2.48-3.47)$ & $<0.001$ \\
\hline Dizziness & $30(17.2)$ & $21(21.2)$ & $51(18.7)$ & $0.77(0.42-1.44)$ & 0.418 \\
\hline Unusual tiredness & $84(48.3)$ & $27(27.3)$ & $111(40.7)$ & $2.49(1.46-4.24)$ & 0.001 \\
\hline Wounds/irritation in the mouth & $6(3.4)$ & $6(6.1)$ & $12(4.4)$ & $0.55(0.17-1.77)$ & 0.311 \\
\hline Unsteady gait & $12(6.9)$ & $6(6.1)$ & $18(6.6)$ & $1.15(0.42-3.16)$ & 0.789 \\
\hline Tremors & $6(3.4)$ & $9(9.1)$ & $15(5.5)$ & $0.357(0.12-1.04)$ & 0.049 \\
\hline Vision problems & $6(3.4)$ & $12(12.1)$ & $18(6.6)$ & $0.26(0.09-0.71)$ & 0.006 \\
\hline Hearing difficulties & $6(3.4)$ & $6(6.1)$ & $12(4.4)$ & $0.55(0.17-1.77)$ & 0.311 \\
\hline Persistent cough & $54(31.0)$ & $9(9.1)$ & $63(23.1)$ & $4.50(2.11-9.59)$ & $<0.001$ \\
\hline Chest pain & $18(10.3)$ & $3(3.0)$ & $21(7.7)$ & $3.69(1.06-12.87)$ & 0.029 \\
\hline Frequent rhinitis & $72(41.4)$ & $33(33.3)$ & $105(38.5)$ & $1.41(0.84-2.36)$ & 0.189 \\
\hline Metallic taste & $0(0.0)$ & $0(0.0)$ & $0(0.0)$ & & \\
\hline Weight loss & $24(14.3)$ & $12(12.1)$ & $36(13.5)$ & $1.21(0.58-2.54)$ & 0.617 \\
\hline Chronic skin changes & $18(10.7)$ & $6(6.1)$ & $24(9.0)$ & $1.86(0.713-4.86)$ & 0.199 \\
\hline Breathlessness & $6(3.6)$ & $0(0.0)$ & $6(2.2)$ & $1.61(1.47-1.77)$ & 0.057 \\
\hline Paresthesia & $0(0.0)$ & $0(0.0)$ & $0(0.0$ & a & a \\
\hline Muscle weakness & $0(0.0)$ & $0(0.0)$ & $0(0.0)$ & a & a \\
\hline At least one symptom & $150(86.2)$ & $57(57.6)$ & $207(75.8)$ & 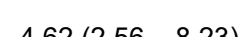 & $<0$ \\
\hline None & $24(13.8)$ & $42(42.4)$ & $66(24.2)$ & $4.02(2.50-8$. & $<0.001$ \\
\hline$\geq 4^{\mathrm{b}}$ symptoms & 48 (27.6) & $15(15.2)$ & $63(23.1)$ & $2 / 1,12,1$ & 9 \\
\hline$<4^{\mathrm{C}}$ symptoms & $126(72.4)$ & $84(84.8)$ & $210(76.9)$ & $2.10(1.12-4.00)$ & 19 \\
\hline
\end{tabular}

a no statistics are computed because feature is a constant

${ }^{b}$ number of symptoms above $75^{\text {th }}$ percentile.

${ }^{c}$ number of symptoms below $75^{\text {th }}$ percentile. 
Table 8. Whole blood mercury and lead concentrations among miners.

\begin{tabular}{ccccc}
\hline Blood sample & Sample size $(\mathrm{N})$ & Range & Mean \pm SD & CDC reference value $(\mu \mathrm{g} / \mathrm{L})$ \\
\hline $\mathrm{Hg}(\mu \mathrm{g} / \mathrm{L})$ & 44 & $0-40$ & $2.27 \pm 8.59$ & $<10$ \\
$\mathrm{~Pb}(\mu \mathrm{g} / \mathrm{L})$ & 44 & $0-110$ & $12.73 \pm 32.73$ & $<100$ \\
\hline
\end{tabular}

Table 9. Spearman's rho correlations between blood $\mathrm{Hg}$ concentrations and clinical features of exposures.

\begin{tabular}{ccccccc}
\hline \multirow{2}{*}{ Blood Hg levels } & *Number of symptoms of Hg toxicity & Total & \multirow{2}{*}{ P-value } & Correlation coefficient \\
& $0-3$ & $4-10$ & $\geq 11$ & $\mathrm{~N}(\%)$ & & \\
\hline & $\mathrm{N}(\%)$ & $\mathrm{N}(\%)$ & $\mathrm{N}(\%)$ & $(\%)$ & $0.519^{* *}$ \\
\hline$\geq 10 \mu \mathrm{g} / \mathrm{L}$ & $0(0.0)$ & $2(16.7)$ & $2(100.0)$ & $4(9.1)$ & $<0.0005$ & \\
$<10 \mu \mathrm{g} / \mathrm{L}$ & $30(100)$ & $10(83.3)$ & $0(0.0)$ & $40(90.9)$ & \\
\hline
\end{tabular}

${ }^{*}$ Number of symptoms according to quartiles $(0-25 \%, 25-75 \%, 75-100 \%)$ (Saulo, et al., 2004).

${ }^{* *}$ Correlation is significant at the 0.01 level (2-tailed).

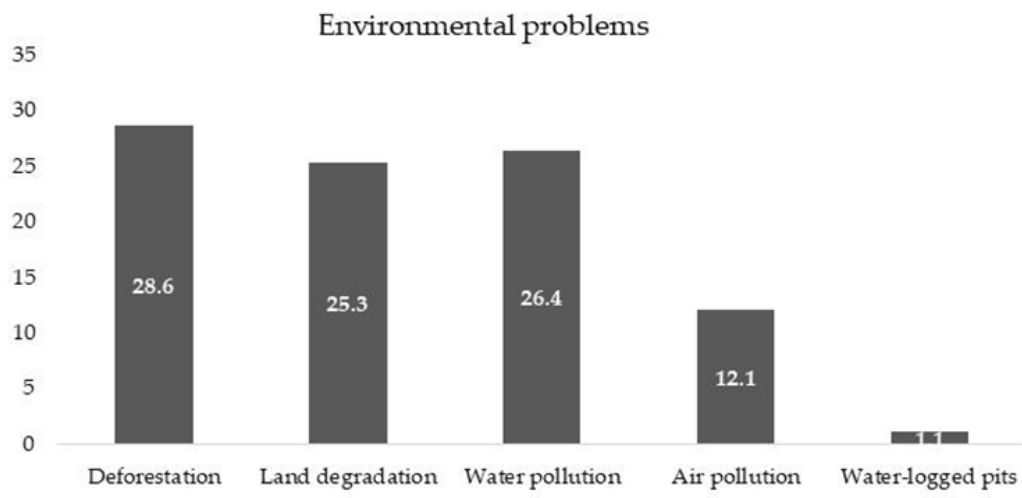

Figure 4. Environmental problems caused by AGM.

Vulnerable elements to environmental problems

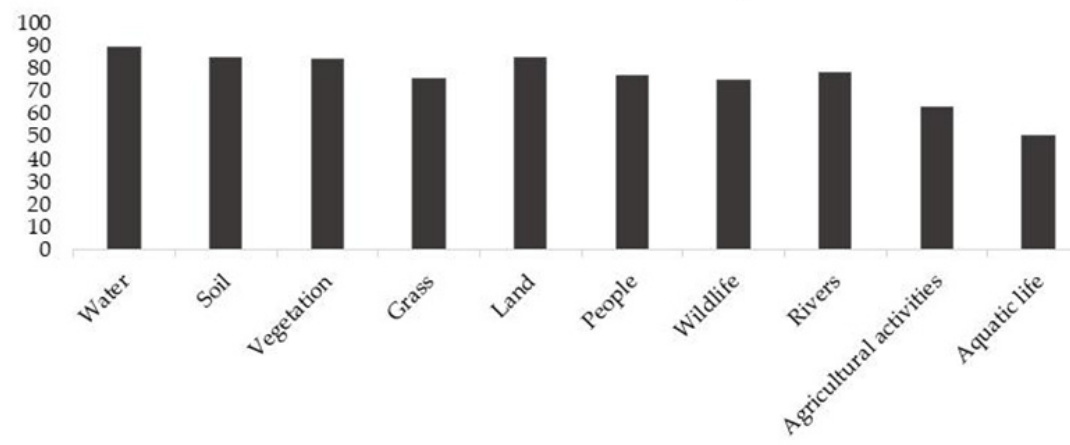

Figure 5. Vulnerable elements 


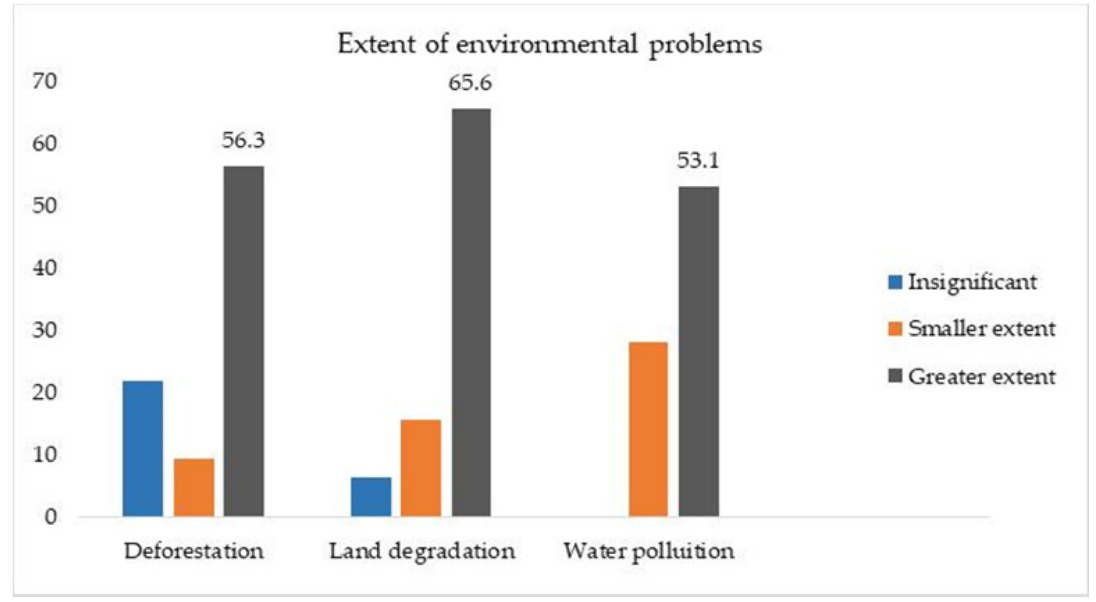

Figure 6. Extent of environmental damage caused by AGM.

\section{Discussion}

\subsection{Occupational health and safety risks in mining}

Very few publications have addressed the OHS risk assessment in small-scale mining. This is because of the informal nature of this type of exploitation. In Cameroon, there is no formal OHS system for the mining sector and few literatures have addressed this issue.

As regards AGM in Batouri, the hazard identification and risk assessment was conducted through a stratification of the entire mining process into 5 different workplaces, and description of specific tasks and tools. This is similar to the method applied by Myriam and Christophe in Katanga (Myriam \& Christophe, 2011). Though similar hazards and risks were identified, our study went further to classify these risks as "High" (intolerable), "Medium (needing efforts to reduce the risk) and "Low" (tolerable).

The suspension of siliceous dust particles in air exposes diggers, millers and crushers to the risk of respiratory conditions like silicosis and COPD. Generally, the prevalence of respiratory symptoms was higher among miners when compared to non-miners. In our study, $6(3.6 \%)$ miners complained of breathlessness on exertion while there were none in the stakeholder sub-group. Though this was not significant $(P=0.057)$, these findings are similar to those reported by Roland (2003) who pointed that the high prevalence of silicosis (massive lung fibrosis marked by breathlessness) among RSA miners was as a result of inhalation of siliceous dust particles in air (Ronald, 2003). Cough was also prevalent among miners $(31.0 \%)$ than stakeholders, $(9.1 \%)$, [OR for cough $=4.50,(2.11-9.59,95 \% \mathrm{Cl}, \mathrm{p}<0.001]$. This is also supported by the findings of Myriam and Christophe (2011), who reported $17.5 \%$ miners with cough, when compared to $10.2 \%$ nonminers [OR for cough $=8.09,(1.86-35.25$ 95\% Cl)] (Myriam \& Christophe, 2011). Other respiratory symptoms in our study like chest pain [OR $=3.69,(1.06-12.87,95 \% \mathrm{CI}) \mathrm{P}=0.029$ ] were relatively more prevalent among the miners sub-group.

The miners in our study also showed increased risk to physical injuries from rock falls, collapse of pit walls and collapse of galleries. These injuries can be fatal or result in disabilities. The mean number of deaths per year as a result of mining reported was approximately $6 \pm 3$ deaths. It would be reasonable to conclude that these fatalities could have been improperly reported as there was no documented source of data. Saulo, et al., (2004) reported approximately 2 - 5 lethal accidents every year in Indonesia. The most common causes of deaths reported in our study were collapse of galleries $(65.8 \%)$, landslides $(31.6 \%)$ especially during the rainy seasons, and others $(2.6 \%)$ such as falls from heights, drowning in water-logged pits and bad communication with 
working equipment. Work accidents were frequent i.e., occurring every week to months. Roland (2003), had similar findings, where he reported at least 28 miners being killed by land slide in Columbia and many reported missing. He concludes that fatalities in mining are grossly underreported (Ronald, 2003). Hentschel et al., (2002) support that rock falls and subsidence are among the five most frequently cited causes of accidents in small-scale mines, according to ILO (Thomas, Felix, \& Micheal, 2002).

The hazards non-specific to various workplaces included alcohol consumption, cigarette smoking, child labor, labor of nursing mothers, and labor of pregnant women. A case of death was reported in one company in Batouri, in which the decedent was discovered dead early in the morning, in a water-logged pit. Witnesses reported that he had been under the influence of alcohol during the night-working shift.

Child labor predisposes children to risk of not going to school, accidents and problems in the physical and psychological development. This is contrary to the new ILO convention to eliminate child labor in mining (Thomas, Felix, \& Micheal, 2002). Labor of nursing mothers is also hazardous. The mining occupational environment is risky for children and babies, who are a more vulnerable group. One case of death of a 2-year-old baby was observed during the field work in which the decedent had been struck by an accidentally falling wood branch from a tree, under which she had been laid to sleep by her mother who had been busy panning for gold. Labor of pregnant women is also a hazard as it exposes these women to increased risk of abortion and congenital anomalies.

These problems in mines are as a result of poor knowledge on health and safety. None of the miners in our study used PPEs like dust masks, boots, helmets, or gloves on regular basis. Also the unhygienic nature of the occupational environment characterized by absence of toilets, garbage bins, hand washing stations etc., could have contributed to contamination risks like diarrheal conditions. These findings are similar to those of Myriam and Christophe (Myriam \& Christophe, 2011).

\subsection{Major health problems among miners and stakeholders}

Though a majority $(50.5 \%)$ reported no relevant medical conditions, the major health problems faced by miners in our study were musculoskeletal problems $(35.6 \%)$, malaria $(26.4 \%)$, hernias $(14.9 \%)$, fatigue $(8.0 \%)$, diarrheal conditions $(5.7 \%)$, accidents $(4.6 \%)$, respiratory conditions $(3.4 \%)$ and STDs $(1.1 \%)$. The stakeholders on other hand complained of malaria (15.2\%), musculoskeletal problems $(6.1 \%)$ and diarrheal conditions $(3.0 \%)$. This finding is supported by various studies that reported diseases in mining communities like Samuel et al., 2007 in Cameroon (Samuel, Charles , \& Gilbert, 2007), Williams et al., 2016 in Ghana (Williams, Joseph, Razak, Charlotte, \& Francis, 2016) and Saulo et al., 2004 in Indonesia (Saulo, et al., 2004).

Though Samuel (2007) also confirmed that most miners appeared physically well fit, he never reported any relevant statistics on the health problems observed. Malaria, skin conditions and respiratory conditions were among the top health problems reported by Williams, et al., (2016) which was not the case in our study. This difference could have been as result of a difference in the mining methods employed in the different settings. The high prevalence of musculoskeletal problems and hernias reported in our study was as a result of the strenuous manual tasks involved due to lack of adequate working materials.

The high prevalence of malaria in the mining communities of Kambéle $(37.5 \%)$ and Dem $(13.8 \%)$ when compared to the non-mining community, Batouri town $(10.0 \%)$, was as a result of the existence of many water-logged pits and trenches in the mining communities which served as breeding sites for mosquitoes which are vectors for spread of the malaria parasite. This result is similar to that reported by Williams et al., (2016) in Ghana.

There were 6 miners $(3.4 \%)$ in our study with HIVIAIDS and on treatment (Table 4). It would be reasonable to conclude that the actual prevalence of HIV among miners in this study could be higher than this value as most miners did not know their HIV status, and serological tests were not conducted in this study. This is as a result of poor knowledge on sexual education in the mining communities when compared with the non-mining community. Saulo et al., (2004) (Saulo, et al., 2004) reported 1 HIV positive case in Tatelu, Indonesia. Though there could be a difference with 
our findings, this supported the notion held by several authors that HIV is more prevalent in mining communities. Kwesi and Kwasi (2001) went further to show that the high prevalence of HIV in mining communities was due to increased incidence of sex trade probably as a result of influx of foreign mining exploitation companies (Kwesi \& Kwasi, 2011).

Our study also reported 6 miners with breathlessness on exertion. These subjects needed chest radiographs to confirm or refute COPD or silicosis, which was not part of our objectives. Similar finding was also reported by Roland (2003) who further reported increased frequency of cancer of the lung, stomach, liver, pulmonary tuberculosis, silicosis and certain insect-borne diseases like dengue fever, which also were not reported in our study.

Finally, our study also proved that these diseases were generally more prevalent in the mining communities when compared to the non-mining communities. Generally, $55.8 \%$ of the respondents affirm the relationship of these diseases with mining. Table 5 above shows that people living in the mining communities are twice likely to suffer from these disease conditions than those living in the non-mining communities [OR $=2.16,(1.03-4.5295 \% \mathrm{Cl}), P=0.038$ ], and miners are four times more likely to suffer from these health problems than stakeholders [OR $=4.36,(2.55-7.47,95 \%$ Cl), $P<0.0005]$. These findings are similar to those of Williams et al., (2016) but he never established any statistical relationship between these medical conditions with mining.

\subsection{Toxic health effects of mercury and lead}

The Cameroon mining code forbids the use of mercury for gold amalgamation due to its toxic health effects. This study was preferably conducted in Batouri than in Bétaré-Oya, the most renowned gold mining district in Cameroon, because it was believed that the fine nature of the gold ore in Batouri attracted the clandestine use of $\mathrm{Hg}$ for amalgamation. There is a paucity of literatures in Cameroon so far which have reported blood $\mathrm{Pb}$ and $\mathrm{Hg}$ concentrations among miners.

Mercury is a multi-organ toxic substance affecting mainly the CNS, kidneys and mucous membranes, and producing non-specific symptoms. The mean blood mercury concentration among miners in our study was $2.27 \pm 8.58 \mu \mathrm{g} / \mathrm{L},(\mathrm{n}=44)$ (Table 8$)$. This is slightly higher the $2 \mu \mathrm{g} / \mathrm{L}$ for unexposed individuals, and less than the occupational toxic threshold of $10 \mu \mathrm{g} / \mathrm{L}$ according CDC (WHO, 2003).

An intoxication is defined as the presence of a toxin in the body above the occupational toxic threshold and typical adverse health effects (Viega \& Baker, 2003). We therefore tried to find a balanced result by a combination of mercury concentration in blood and negative health effects. The number of symptoms were divided into three different quartiles $(0-25 \%, 25-75 \%, 75-$ $100 \%)$ as shown in Table 9 above. There were $4(9.1 \%, P<0.001)$ miners with $\geq 4$ symptoms (i.e., in the upper quartiles division) identified with blood mercury above toxic threshold. Saulo et al., (2004) in his own study reported higher prevalence $(23.5-54.1 \%)$ of chronic mercury intoxication in Indonesia (Saulo, et al., 2004). This difference could have been as a result of the relatively heavy use of mercury by amalgam burners in their setting, which was not the case in our setting since miners in our study were aware about the forbidden use of mercury by the Cameroon mining code. This low prevalence in our study could also be as a result of sampling errors. Also, $23.1 \%$ miners in our study reported $\geq 4$ symptoms possibly relating to mercury exposure, irrespective of their blood $\mathrm{Hg}$ levels. This is small when compared to the more than $50 \%$ miners reporting $\geq 5$ symptoms in Burkina Faso, reported by Tomicic et al., (2011) (Herman \& Keri, 2014).

Lead is a major heavy metal in gold-sulphide deposits occurring as galena (PbS). Human exposure is usually through drinking of water or consumption of food grown in this soil. The mean lead concentration among miners in our study was $12.73 \pm 32.73 \mu \mathrm{g} / \mathrm{L}(\mathrm{n}=44)($ Table 8$)$. This is far less than the toxic threshold of $100 \mu \mathrm{g} / \mathrm{L}$ according CDC. Authors like Jason et al., (2002) have reported high lead contents in soil and water samples in gold mining communities, which was not part of our objectives for this study. We had similar results $(<20 \mu \mathrm{g} / \mathrm{L})$ with Zahra et al., (2015) in Iran, even though he was looking at the relationship of blood $\mathrm{Pb}$ levels with multiple sclerosis. Yasmin et al., (2003) reported mean BLLs up to $159 \mu \mathrm{g} / \mathrm{L}$ and $132 \mu \mathrm{g} / \mathrm{L}$ in two subgroups of children in a lead mining but not gold mining community, in South Africa. 


\subsection{Environmental problems caused by $A G M$}

The environmental problems reported in this study were deforestation (28.6\%), land degradation $(25.3 \%)$, water pollution $(26.4 \%)$, air pollution $(12.1 \%)$ and existence of water-logged pits $(1.1 \%)$ (Figure 5). The Kadei river, the main source of portable water for the population of Batouri, has been heavily polluted by companies which have mined gold directly on it through dredging. This explains the poor quality of the pipe borne water in Batouri, which is characterized by many episodes of flows with coloration. The Djengou river in Kambélé is also heavily polluted by mining.

Deforestation causes loss of natural resources and biodiversity. Land degradation is associated with loss of cultivable land. Air pollution is a hazard for respiratory conditions. The many abandoned pits cause disturbance of land surfaces and also serving as breeding sites for mosquitoes. A semi-quantitative assessment of the extent of these problems was carried out, where respondents were asked to report them as either "insignificant", "smaller extent", or "greater extent." It was observed that deforestation, land degradation and water pollution were of greater extent (Figure 7.)

AGM in Batouri is poverty-driven. Most miners engage in this activity to earn a living. Compromising these negative impacts with the promotion of AGM can be cumbersome. However, though there are regulations and policies governing mining, it appears that these policies are not respected, since a greater proportion of the miners in Batouri $(76.9 \%)$ were unaware of these policies (Table 1). This therefore appears to be the main cause of these adverse environmental impacts.

These environmental problems have also been reported by several authors. Joseph et al., (2013) showed that the Mari River of Bétaré-Oya in East Cameroon, and its plains were dominated by the remains of AGM. Suh (2012) and Samuel, et al., (2007) also reported similar results, but these authors never reported the extent of environmental damage. Kwesi and Kwasi (2011) in Ghana showed that the principal elements affected by mining were land, water and air.

\section{Conclusion and recommendation}

\subsection{Conclusion}

The results of the study show that gold miners in Batouri are exposed to the risks of physical injuries, respiratory conditions, diarrheal conditions, psychotic disorders, dermatophyte infections, helminthic infestations, malaria and musculoskeletal problems. The most common health problems faced by miners are musculoskeletal disorders (35.6\%), malaria $(26.4 \%)$ and hernias $(14.9 \%)$, while malaria $(18.7 \%)$ and musculoskeletal problems (15.4\%) are common among stakeholders. Miners show increased blood mercury and lead concentrations, and $9.1 \%(P<0.001)$ of them are chronically intoxicated with mercury, reporting $\geq 4$ symptoms possibly relating to mercury intoxication. The major environmental problems caused by mining are deforestation, land degradation, water pollution, air pollution and water-logged pits, and these problems are of greater extent. Since healthy and safe working conditions are among the first expectations for sustainability AGM in Batouri, therefore, has a negative implication on sustainable development.

\subsection{Recommendations}

In view of the results obtained, the following recommendations are hereby suggested:

1. The Ministry of Labor and Social Security should create an OHS system for the mining sector in Cameroon, which would train miners on health and safety, and properly investigate and report work accidents in mines.

2. The Ministry of Industry, Mines and Technological Development should re-enforce the mining policies in all mining districts in Cameroon.

3. The Ministry of Public Health should create more health facilities, and re-enforce portable water points in mining districts.

4. The Ministry of Scientific Research and Innovation should encourage research on Chest 
X-ray studies and kidney function tests among miners to further investigate for any endorgan damage from heavy metal exposure.

\section{Acknowledgments}

This article is part of the MD thesis of O. M. Ralph, at the University of Buea under supervision by Dr. Peter NDE FON and Prof. Henry LUMA. Logistic and administrative supports were provided by the Support and Promotion Framework of Small Scale Mining (CAPAM) in Cameroon. This work was funded by the Presbyterian Church in Cameroon (PCC), Great Soppo, Buea, and Explorer's 33 Consulting Agency Yaoundé. Prof. MVONDO Le Antoine David in the Department of Agronomy and Agriculture of the University of Dschang, helped with analysis of the blood samples by Atomic Absorption Spectrometry.

\section{References}

Asaah, V. (2010). Lode gold mineralization in the neoproterozoic granitoids of Batouri, southeastern Cameroon. Doctoral Thesis. Cameroon: Technical University of Clausthal, Clausthal Zellerfield, Germany. Retrieved from http://www.gbv.de/dms/clausthal/E_DISS/2010/db109832.pdf. Accessed 10/05/2012

Bernd, D., Jennifer, H., \& Manfred, W. (2010). An Occupational Safety Health System For Small Scale Mines in Rwanda. . Rwanda : Projekt-Consult Gmbh .

Borralho, C. (2013, August 2). Gold mining affects mineworkers' health.

Cheo, E. S. (2012). Mining And The Environment: driving balanced growth through research communication. Conference. Cameroon: RIMI4AC \& CARIMA Lauch.

District Health Service Batouri. (2015). Monthly Vaccination Surveillance Program of the Batouri Health District. Cameroon: Ministry of Public Health.

Herman, G., \& Keri, G. O. (2014, July 7). Mercury Exposure and Health Impacts among Individuals in the Artisanal and SmallScale Gold Mining Community:. Environmental Health Perspectives, 122, 2-3. Retrieved November 26, 2013, from http://dx.doi.org/10.1289/ehp.1307864

Hermanus, M. A. (2007). Occupational health and safety in mining - status, new developments, and concerns. The Southern African Institute of Mining and Metallurgy, 107, 531-538.

Jason, S. O., Winnie, V. M., \& Monica, A. O. (2002). Impact of Gold Mining on the Environment And Human Health: A Case Study in the Migori Gold Belt, Kenya. Environmental Geochemistry and Health(24), 141-158.

Joseph, P., \& Joseph, V. H. (2013). Abandoned artisanal gold mining sites of Eastern Cameroon: environmental problems and Cameroon regulation. Johannesburg: Institute for Geological and Mining Research, BP 4110 Yaounde Cameroon.

Kwesi, A.-T., \& Kwasi, D.-B. (2011). The Mining Industry in Ghana: A blessing or a Curse. International Journal of Business and Social Science, 2(12), 62-69. Retrieved from http://www.ijbssnet.com

Kwesu, N., \& Zhanje, S. (2004). Business Statistics.

Mbianyor, B. (2014). East Cameroon's Artisanal and Small Scale Bonanza: How long will it last? 62,40-50.

Myriam, M. E., \& Christophe, D. B. (2011). Identification of Hazards in the Workplaces of Artisanal Mining in Katanga. International Journal of Occupational Medicine and Environmental Health(24(1)), 57-66. doi:10.2478/s13382-011-0012-4

Rasheed, I., \& Amuda, A. (2014, November). Impacts of Artisanal Mining on Some Heavy Metals Concentration in Surface Water in Kutcheri, Zamfara State Northe-Western Nigeria. Academic Journal of Interdisciplinary Studies, 3(7), 74-82. doi:10.5901/ajis.2014.v3n7p74

Ronald, E. (2003). Health Risks of Gold Miners: A synoptic review. Environmental Geochemistry and Health(25), 325-345. Retrieved June 10, 2002

Samuel, M. (2011). Environmental and Occupational Health in Cameroon.

Samuel, T., Charles, N., \& Gilbert, K. (2007). Environmental and Socio-economic assessment of an Artisanal Gold Mine field: case of Bétaré-Oya, East-Cameroon. Yaoundé: Centre de Recherche et d'Education pour le Développement (CREPD), P.O. Box 31314, Yaoundé, Cameroun.

Saulo, R. P., Correa, R. L., Castihos, Z. C., Villas, R. C., Yallouz, A. V., Peregovich, B., . . Martins, L. R. (2004). Environmental and Health Assessment in Two Small-Scale Gold Mining Areas - Indonesia. Ludwig-Maximilians University, Munich, Germany, Institute of Forensic Medicine. Brazil: Centro de Tecnologia Mineral (CETEM).

Seydou, K. (2002, August). Artisanal and Small-Scale Mining in Mali. Mining, Mineral and Sustainable Development (MMSD).

The World Bank. (2013). Artisanal Mining in Criticlal Ecosystems: A Look At Gabon, Liberia, and Madagascar. Washington DC 20433: The World Bank, African Region.

Thomas, H., Felix, H., \& Micheal, P. (2002). Global Report on Artisanal \& Small-Scale Mining. MMSD (Mining, Minerals and Sustainable Development), 70, 36-37.

Tieguhong, J. C., Verina, I., \& Jolien, S. (2009). Impacts of artisanal gold and diamond mining on livelihoods and environment in the Sangha Tri-National Park landscape. Bogor, Indonesia: Center for International Forestry Research (CIFOR). Retrieved from www.cifor.cgiar.org

Tiffany, F. (2012). Extractive industries in Cameroon: Source book for teachers. Yaoundé, Center Region, Cameroon: Reseau de Lutte Contre la Faim au Cameroun (RELUFA), BP 1003 Yaoundé - Cameroun. Retrieved from www.reluf.org

UNEP/OCHA. (2010). Lead Pollution and Poisoning Crisis Environmental Emergency Response Mission, Zamfara State, Nigeria. Switzerland: The Joint UNEP/OCHA Environmental Unit.

Viega, M., \& Baker, R. (2003). Protocols for Environmental and Health Assessment of Mercury Released by Artisanal and 
Small-Scale Gold Miners. UNIDO.

WHO (World Health Organization). (2003). Elemental Mercury and Inorganic Mercury Compounds: Human Health Aspects. Concise Internatioinal Chemical Assesssment Document, 50. Retrieved October 15, 2013, from http://www.who.int/ipcs/publications/cicad/en/cicad50.pdf

Williams, A.-D., Joseph, Y. Y., Razak, M. G., Charlotte, M. M., \& Francis, A. (2016, February 5). Mining and Public Health Implications: Evidence from the Newmont Ghana Gold Limited Enclaves. Research Journal of Applied Sciences, Engineering and Technolgy, 12(3), 272-281. doi:10.19026/rjaset. 12.2323

Yasmin, v. S., Angela, M., Maurice, K., Priscilla, R., Nicolene, S., \& Reinette, B. (2003). A study of pediatric blood lead levels in a lead mining area in South Africa. Environmental Research, 93, 259-263. Retrieved September 10, 2002, from http://www.elsevier.com/locate/envrs

Zahra, R., Mojtaba, J., Alireza, A., Zahra, H., Leila, B., \& Vahid, S. N. (2015, December 29). The Relationship Between Blood Lead Levels and Clinical Features Among Multiple Sclerosis Patients in Isfahan, Iran. Iranian Journal of Health, Safety and Environment, 3(1), 412-420. Retrieved November 23, 2015

\section{Appendices}

\section{Appendix 1.}

Workplace Inspection Checklist

Work Area:

Date:

Name of Inspector:

\begin{tabular}{|c|c|c|}
\hline \multicolumn{3}{|c|}{ Manager on duty: } \\
\hline \multicolumn{2}{|c|}{ FEATURE INSPECTED } & $\begin{array}{l}\text { Standard Met? } \\
Y=\text { Yes } \\
N=\text { No } \\
\text { N/A = not applicable }\end{array}$ \\
\hline \multicolumn{3}{|c|}{ Employees and subcontracted workers } \\
\hline \multicolumn{3}{|c|}{ 1. Supervision } \\
\hline a) & Area/site manager on the job & \\
\hline b) & Security checkpoint at entrance & \\
\hline c) & Access restricted sign at entrance & \\
\hline d) & Head count registry in use & \\
\hline \multicolumn{3}{|c|}{ 2. Personal Protection } \\
\hline a) & Head protection (e.g. helmets) & \\
\hline b) & Footwear (e.g. boots) & \\
\hline c) & Hand protection (e.g. gloves) & \\
\hline d) & Protective clothing (e.g. jackets) & \\
\hline e) & Eye protection (goggles) & \\
\hline f) & Face protection (face mask) & \\
\hline g) & Ear protection & \\
\hline h) & Protection from dust (dust masks) & \\
\hline \multicolumn{3}{|l|}{ 3. General } \\
\hline a) & A stocked First Aid Kit is on-site & \\
\hline b) & At least 1 of 10 workers per group on-site is a trained First Aider & \\
\hline c) & Workers wearing visible ID cards & \\
\hline d) & Only authorized persons on-site & \\
\hline e) & Persons observed under influence of drugs or alcohol & \\
\hline f) & $\begin{array}{l}\text { Incidences of verbal, physical or sexual abuse or harassment observed or } \\
\text { reported }\end{array}$ & \\
\hline \multicolumn{3}{|c|}{ General Conditions } \\
\hline \multicolumn{3}{|c|}{ 4. Sanitation and Hygiene } \\
\hline a) & All pit latrines for men are clean and in good condition & \\
\hline b) & All pit latrines for women are clean and in good condition & \\
\hline c) & All hand washing stations are clean and stocked with water and soap & \\
\hline d) & Hand-washing signs visible & \\
\hline e) & Adequate supply of clean drinking water is available & \\
\hline f) & All areas are kept free of rubbish and debris & \\
\hline g) & Clearly marked garbage/rubbish bins have been emptied & \\
\hline h) & Separate areas for eating are available and are clean and tidy & \\
\hline \multicolumn{3}{|c|}{ Surface Mining } \\
\hline \multicolumn{3}{|c|}{ 5. Pit wall stability } \\
\hline a) & Overburden is stripped at least $3 \mathrm{~m}$ back from the pit wall edge & \\
\hline & $\begin{array}{l}\text { Overburden at waste rock is stockpiled at least } 10 \mathrm{~m} \text { back from the pit wall } \\
\text { edge }\end{array}$ & \\
\hline c) & Undercutting of overburden? & \\
\hline
\end{tabular}




\begin{tabular}{|c|c|c|c|}
\hline \multicolumn{2}{|c|}{ d) } & Undercutting of pit walls? & \\
\hline \multicolumn{2}{|r|}{ e) } & $\begin{array}{l}\text { Major fractures, evidence of wall rock falling or signs of movement or shifting } \\
\text { of pit wall }\end{array}$ & \\
\hline \multicolumn{2}{|r|}{ f) } & $\begin{array}{l}\text { Major cracks on surface parallel to foot wall edge or heaving at the toe of the } \\
\text { pit wall }\end{array}$ & \\
\hline \multicolumn{2}{|r|}{ g) } & $\begin{array}{l}\text { Waste rock berms constructed } 2-4 \mathrm{~m} \text { from wall bottom where heaving of the } \\
\text { toe observed }\end{array}$ & \\
\hline \multicolumn{2}{|r|}{ h) } & Long metal rods on site and in use for scaling of loose rock & \\
\hline \multicolumn{2}{|r|}{ i) } & Pit bottom evacuated before scaling & \\
\hline \multicolumn{2}{|r|}{ j) } & $\begin{array}{l}\text { For pits deeper than } 4 \mathrm{~m} \text {, benches are located at least every } 2 \mathrm{~m} \text { and are } \\
\text { good condition }\end{array}$ & \\
\hline \multicolumn{3}{|c|}{ 6. Access Paths, Ramps and Roads } & \\
\hline \multicolumn{2}{|r|}{ a) } & $\begin{array}{l}\text { Access paths and ramps show no signs of collapse or cracking, standing } \\
\text { water and are in good condition }\end{array}$ & \\
\hline \multicolumn{2}{|r|}{ b) } & Access paths and ramps are free of obstructions & \\
\hline \multicolumn{2}{|r|}{ c) } & $\begin{array}{l}\text { Access paths and ramps are of sufficient width to enable passage of any } \\
\text { haulage/transport equipment used (wheelbarrows, trucks, persons) }\end{array}$ & \\
\hline \multicolumn{3}{|c|}{ 7. Mine Water } & \\
\hline \multicolumn{2}{|r|}{ a) } & $\begin{array}{l}\text { Drainage ditches are dug, where needed to direct run-off water away from } \\
\text { the pit }\end{array}$ & \\
\hline \multicolumn{2}{|r|}{ b) } & $\begin{array}{l}\text { Drainage ditches are dug on the inside (pit wall side) or haul ramps and } \\
\text { paths and are clear of debris and obstructions }\end{array}$ & \\
\hline \multirow{2}{*}{\multicolumn{2}{|c|}{ c) }} & Water ramps are in-use and functioning properly in areas where needed & \\
\hline & & $\begin{array}{l}\text { Pumped water not required for other purposes is directed to a dug or natural } \\
\text { sedimentation basin which is not clogged and functioning properly }\end{array}$ & \\
\hline
\end{tabular}

Appendix 2. Risk Analysis Form

\begin{tabular}{|c|c|c|c|c|}
\hline \multicolumn{5}{|c|}{ ARTISANAL GOLD MINING RISK ANALYSIS FORM } \\
\hline \multicolumn{5}{|l|}{ Work area } \\
\hline \multicolumn{5}{|c|}{ Form completed by: } \\
\hline \multicolumn{5}{|c|}{ Date of completion: } \\
\hline \multicolumn{2}{|c|}{ Hazard identification } & \multicolumn{3}{|l|}{ Hazard } \\
\hline \multirow{8}{*}{\multicolumn{2}{|c|}{ 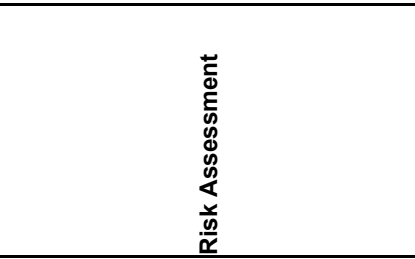 }} & \multicolumn{3}{|c|}{ What could happen } \\
\hline & & \multicolumn{3}{|c|}{ How it can happen } \\
\hline & & \multicolumn{3}{|c|}{ Why it can happen } \\
\hline & & \multicolumn{3}{|l|}{ Persons at risk } \\
\hline & & \multicolumn{3}{|c|}{ Mode of exposure to hazard } \\
\hline & & \multicolumn{3}{|c|}{ Existing control measures } \\
\hline & & \multicolumn{3}{|c|}{ Likelihood of exposure } \\
\hline & & \multicolumn{3}{|c|}{ Consequence of exposure } \\
\hline Risk & & \multicolumn{3}{|c|}{ [Likelihood] X [Consequence] } \\
\hline \multicolumn{3}{|c|}{ Likelihood of exposure } & \multicolumn{2}{|c|}{ Consequence of exposure } \\
\hline \begin{tabular}{|l|l|} 
L1 & Almost certain \\
\end{tabular} & \multicolumn{2}{|c|}{ Happens every time we operate (daily) } & \begin{tabular}{|l|l|} 
C1 & Catastrophic \\
\end{tabular} & Sudden death or death after prolonged disease \\
\hline \begin{tabular}{|l|l|} 
L2 & Likely \\
\end{tabular} & \multicolumn{2}{|c|}{ Happens regularly (every 2 months) } & \begin{tabular}{|l|l|} 
C2 & Major \\
\end{tabular} & permanent disability \\
\hline \begin{tabular}{|l|l|} 
L3 & Possible \\
\end{tabular} & \multicolumn{2}{|c|}{ Has happened (yearly) } & \begin{tabular}{|l|l|} 
C3 & Moderate \\
\end{tabular} & Reversible injury needing hospitalization or lost time \\
\hline \begin{tabular}{|l|l|l|l} 
L4 & Unlikely \\
\end{tabular} & \multicolumn{2}{|c|}{ Happens irregularly (10-yearly) } & \begin{tabular}{l|l} 
C4 & Minor \\
\end{tabular} & First aid or no lost time \\
\hline \begin{tabular}{|l|l|} 
L5 & Rare \\
\end{tabular} & \multicolumn{2}{|l|}{ Improbable (never) } & \begin{tabular}{|l|l|} 
C5 & Insignificant \\
\end{tabular} & No injury \\
\hline
\end{tabular}

\begin{tabular}{|c|c|c|c|c|c|c|}
\hline \multicolumn{7}{|c|}{ Interpretation Of Likelihoods And Consequences Of Hazards. } \\
\hline \multicolumn{2}{|c|}{ Risk Rank = [Likelihood] $x$ [Consequence $]$} & $\begin{array}{l}\text { L1 } \\
\text { Almost certain }\end{array}$ & $\begin{array}{l}\text { L2 } \\
\text { Likely }\end{array}$ & $\begin{array}{l}\text { L3 } \\
\text { Possible }\end{array}$ & $\begin{array}{l}\text { L4 } \\
\text { Unlikely }\end{array}$ & $\begin{array}{l}\text { L5 } \\
\text { Rare }\end{array}$ \\
\hline \multicolumn{2}{|c|}{ C1 Catastrophic } & High & High & High & Medium & Medium \\
\hline \multicolumn{2}{|c|}{ C2 Major } & High & High & Medium & Medium & Low \\
\hline \multicolumn{2}{|l|}{ C3 Moderate } & High & Medium & Medium & Low & Low \\
\hline \multicolumn{2}{|l|}{ C4 Minor } & Medium & Medium & Low & Low & Low \\
\hline \multicolumn{2}{|l|}{ C5 Insignificant } & Medium & Low & Low & Low & low \\
\hline \multicolumn{7}{|c|}{ "Likelihood" times "Consequence" cross-tabulation } \\
\hline \multicolumn{7}{|l|}{ RISK RATING } \\
\hline High Risk & \multirow{3}{*}{\multicolumn{6}{|c|}{$\begin{array}{l}\text { Intolerable: the risk is unacceptable and actions must be taken to reduce it. } \\
\text { As Low As Reasonable Practicable (ALARP): efforts must be made to reduce risk further } \\
\text { without gross expenditure that is disproportionate to benefit. } \\
\text { Tolerable: no actions needed }\end{array}$}} \\
\hline $\begin{array}{l}\text { Medium } \\
\text { Risk }\end{array}$ & & & & & & \\
\hline Low Risk & & & & & & \\
\hline
\end{tabular}

